\title{
Distant Metastasis of Undifferentiated Carcinoma of Nasopharyngeal Type
}

\author{
Yungan Tao François Bidault Jacques Bosq Jean Bourhis \\ Institut Gustave-Roussy, Villejuif, France
}

Nasopharyngeal carcinoma (NPC) is endemic in southern China, south-east Asia and north Africa, where the undifferentiated carcinoma of nasopharyngeal type (UCNT; WHO type 2 and 3) is most frequent [1]. UCNT is an Epstein-Barr virus (EBV)-related carcinoma [2]. NPC has distinctive features from other head and neck squamous cell cancers (HNSCC). These include early subclinical dissemination, with most of distant metastases (DM) appearing within 18 months of first symptoms [3]. The incidence of DM is reported to be more than $30 \%$ in one large series based on 5,037 cases of NPC [4]. Bone is the most frequent metastatic site, followed by lung, and liver $[3,5]$.

In this issue of ONKOLOGIE, Kao et al. [6] report an unusual case of cystic liver metastases form of NPC. The patient has been treated initially by chemo-radiotherapy based on cisplatin and 5-fluorouracil (5-FU) for NPC with bone metastases. The suspicion of liver metastases was found 1 year after the beginning of treatment and confirmed finally by histological examination of liver aspiration with fluid cytology 6 months later. The treatment had been switched to docetaxel and cisplatin as soon as liver metastases were suspected. There are few published studies concerning liver metastasis of NPC although they are not rare, and cystic liver metastasis from NPC is exceptional. This report provides an example of this kind of rare characteristic of NPC metastasis, and may suggest that a special aspect of liver metastases with a cystic form does exist for NPC.

The limitations of this report are obvious, and it is unlikely to provide us with strong clinical practice assistance because of a case study characteristic of this kind of report (Evidence Based Medicine level 5). In fact, cystic lesions in liver could be induced by many factors, such as infectious or congenital diseases, liver injuries, benign tumors or liver metastasis of other malignant tumors (e.g. carcinoid, ovary, pancreas). For the diagnosis, histological confirmation is necessary as shown in the figure of this case study. We may point out that metastases are sometimes more differentiated than primitive nasopharyngeal carcinoma, as shown in this case.
Positron emission tomography (PET) using fluorine-18-labeled fluorodeoxyglucose $\left({ }^{18} \mathrm{~F}-\mathrm{FDG}\right)$ which is a promising method for the early detection of DM of NPC [7] was not mentioned in this case report, although early detection of further liver metastasis might not have changed the clinical practice nor improved patient's survival [8]. It would be interesting to know the intensity of fixation in PET images of this kind of metastatic cystic lesions. The prognosis of patients with liver metastasis is considered to be poorer than lung or bone metastasis [5, 9]. For some kind of solitary liver metastasis, however, surgical resection, radiofrequency ablation or stereotactic body radiotherapy could be valuable treatment options, especially when loco-regional disease has been controlled. Long-term survival has been reported with partial hepatectomy [10].

The authors claim that concurrent chemo-radiotherapy is the standard treatment for metastatic NPC. We may consider this statement with caution. For selected patients with few metastatic sites, additional radiotherapy can provide extended disease control as shown in previous reports. Poly-chemotherapy can be considered as standard of care in patients with metastatic NPC [11]. Cisplatin-based combination chemotherapy is the most effective standard treatment for metastatic NPC. The combination of cisplatin and infusional 5-FU remains the most commonly used in first-line treatment with a $66-76 \%$ response rate. More intensive combinations give a higher response rate, but are also usually associated with increased toxicities. None of these combinations has yet been compared with the combination of cisplatin and 5-FU [1].

Treatment of metastatic NPC is essentially palliative and survival is usually poor. However, a small percentage of patients may be cured by systemic therapy, long-term survival may be obtained in some cases [5, 12]. 20 long-term (more than 36 months) disease-free survivors of metastatic NPC (bone, lung, or liver) from the Institut Gustave-Roussy have been reported using 4 different intensive chemotherapy protocols including cisplatin, bleomycin, 5-FU, epirubicin, or mitomycin. This suggests a potential curative role for chemotherapy in metastatic

\begin{tabular}{ll}
\hline KARGER & ( ) 2008 S. Karger GmbH, Freiburg \\
Fax +497614520714 & Accessible online at: \\
$\begin{array}{l}\text { Information@Karger.de } \\
\text { www.karger.com }\end{array}$ & www.karger.com/onk
\end{tabular}


NPC and as a major incentive to continue research for better combinations to increase the percentage of patients with metastatic NPC who attain complete responses and long-term survival [12].

Agents such as taxanes (paclitaxel, docetaxel) and gemcitabine have demonstrated comparable response rates with favorable toxicity profiles. Other active agents include capecitabine, vinorelbine, and irinotecan, which have been used as single agents or in combination [13]. In this report, docetaxel and cisplatin have been used for the disease progression, however, no further response has been obtained.
Molecular therapies targeting epidermal growth factor receptor (EGFR) have demonstrated efficacy in HNSCC. However, few studies have been reported in NPC and cetuximab has shown its efficacy in combination with carboplatin in a phase II study [14]. On the other hand, other targeted therapies such as gefitinib [15] and sorafenib [16] failed to show any objective response in metastatic NPC. Cell therapy with autologous EBV specific anti-LMP2 cytotoxic T cells has been reported recently in metastatic or advanced NPC and demonstrated encouraging efficacy and safety $[17,18]$. These promising therapies deserve further exploration in the future.

\section{References}

1 Guigay J, Temam S, Bourhis J, Pignon JP, Armand JP: Nasopharyngeal carcinoma and therapeutic management: the place of chemotherapy. Ann Oncol 2006;17 Suppl 10:x304-307.

2 Tao Q, Chan AT: Nasopharyngeal carcinoma: molecular pathogenesis and therapeutic developments. Expert Rev Mol Med 2007;9:1-24.

3 Cvitkovic E, Bachouchi M, Boussen H, Busson P, Rousselet G, Mahjoubi R, Flores P, Tursz T, Armand JP, Azli N: Leukemoid reaction, bone marrow invasion, fever of unknown origin, and metastatic pattern in the natural history of advanced undifferentiated carcinoma of nasopharyngeal type: a review of 255 consecutive cases. J Clin Oncol 1993;11:2434-2442.

$\checkmark 4$ Lee AW, Law SC, Foo W, Poon YF, Cheung FK, Chan DK, Tung SY, Thaw M, Ho JH: Retrospective analysis of patients with nasopharyngeal carcinoma treated during 1976-1985: survival after local recurrence. Int J Radiat Oncol Biol Phys 1993;26: 773-782.

5 Hui EP, Leung SF, Au JS, Zee B, Tung S, Chua D, Sze WM, Law CK, Leung TW, Chan AT: Lung metastasis alone in nasopharyngeal carcinoma: a relatively favorable prognostic group. A study by the Hong Kong Nasopharyngeal Carcinoma Study Group. Cancer 2004;101:300-306.

6 Kao CC, Yu CP, Liu YC, Yu JC, Hsieh CB: Unusual presentation of cystic liver metastases from nasopharyngeal carcinoma. Onkologie 2008;31:635-636.
7 Liu FY, Lin CY, Chang JT, Ng SH, Chin SC, Wang HM, Liao CT, Chan SC, Yen TC: 18F-FDG PET can replace conventional work-up in primary $\mathrm{M}$ staging of nonkeratinizing nasopharyngeal carcinoma. J Nucl Med 2007;48:1614-1619.

8 Guigay J: Advances in nasopharyngeal carcinoma. Curr Opin Oncol 2008;20:264-269.

$\checkmark 9$ Teo PM, Kwan WH, Lee WY, Leung SF, Johnson PJ: Prognosticators determining survival subsequent to distant metastasis from nasopharyngeal carcinoma. Cancer 1996;77:2423-2431.

10 Weitz J, Blumgart LH, Fong Y, Jarnagin WR, D'Angelica M, Harrison LE, DeMatteo RP: Partial hepatectomy for metastases from noncolorectal, nonneuroendocrine carcinoma. Ann Surg 2005;241: 269-276.

11 Wei WI, Sham JS: Nasopharyngeal carcinoma. Lancet 2005;365:2041-2054.

12 Fandi A, Bachouchi M, Azli N, Taamma A, Boussen H, Wibault P, Eschwege F, Armand JP, Simon J, Cvitkovic E: Long-term disease-free survivors in metastatic undifferentiated carcinoma of nasopharyngeal type. J Clin Oncol 2000;18:1324-1330.

13 Ma BB, Chan AT: Recent perspectives in the role of chemotherapy in the management of advanced nasopharyngeal carcinoma. Cancer 2005;103:22-31.
4 Chan AT, Hsu MM, Goh BC, Hui EP, Liu TW, Millward MJ, Hong RL, Whang-Peng J, Ma BB, To KF, Mueser M, Amellal N, Lin X, Chang AY: Multicenter, phase II study of cetuximab in combination with carboplatin in patients with recurrent or metastatic nasopharyngeal carcinoma. J Clin Oncol 2005;23:3568-3576.

15 Chua DT, Wei WI, Wong MP, Sham JS, Nicholls J, Au GK: Phase II study of gefitinib for the treatment of recurrent and metastatic nasopharyngeal carcinoma. Head Neck 2008;30:863-867.

6 Elser C, Siu LL, Winquist E, Agulnik M, Pond GR, Chin SF, Francis P, Cheiken R, Elting J, McNabola A, Wilkie D, Petrenciuc O, Chen EX: Phase II trial of sorafenib in patients with recurrent or metastatic squamous cell carcinoma of the head and neck or nasopharyngeal carcinoma. J Clin Oncol 2007;25: 3766-3773.

17 Comoli P, Pedrazzoli P, Maccario R, Basso S, Carminati O, Labirio M, Schiavo R, Secondino S, Frasson C, Perotti C, Moroni M, Locatelli F, Siena S: Cell therapy of stage IV nasopharyngeal carcinoma with autologous Epstein-Barr virus-targeted cytotoxic T lymphocytes. J Clin Oncol 2005;23: 8942-8949.

18 Straathof KC, Bollard CM, Popat U, Huls MH, Lopez T, Morriss MC, Gresik MV, Gee AP, Russell HV, Brenner MK, Rooney CM, Heslop HE: Treatment of nasopharyngeal carcinoma with Epstein-Barr virus-specific T lymphocytes. Blood 2005;105:1898-1904. 